damaged surface cells was $1 \cdot 7 \pm 0 \cdot 4 \%$ (mean $\pm S E$ ), which was similar to that found previously. ${ }^{9}$ This damage presumably represents normal aging and dying.1011 Scanning electron microscopy of the normal gastric mucosa showed the typical cobblestone appearance of the epithelial surface (fig $1(b)$ ).

Changes induced by paracetamol in saline-Ten minutes after instillation most of the gastric mucosal surface appeared normal. The mean incidence of damaged surface cells was $3.5 \pm 1.5 \%$, which was not significantly different from the control results. Light microscopy showed areas of focal cellular degeneration with loss of toluidinestaining density of cytoplasm, appearance of small vacuoles in the cytoplasm, and degeneration of the nuclear chromatin. These foci of cellular degeneration were infiltrated by red blood cells (fig 2(a)). Scanning electron microscopy showed that most of the mucosa surface was normal, although random areas where the normal cel apices had been lost gave the surface a pitted appearance (fig $2(b)$ ). No erosions were seen by either light or scanning electron microscopy.

Biopsy appearances during recovery period-Light and scanning electronmicrographs of the biopsy specimens taken 60 minutes after paracetamol instillation were similar to the control and 10-minute micrographs. Of the cells counted, $3 \cdot 0 \pm 1 \cdot 6 \%$ were damaged, which was not significantly different from the control values.

In contrast, fig 3(a) shows the appearance of typical gastric erosions present 10 minutes after the ingestion of two aspirin tablets $(600 \mathrm{mg})$ in $100 \mathrm{ml}$ isotonic saline as seen by light microscopy. ${ }^{7} 10$ Fig 3(b) shows the typical extensive aspirin-induced lesions as seen by scanning electron microscopy.

\section{Discussion}

Although paracetamol is commonly used as a substitute for aspirin to avoid gastric mucosal injury, there have been no studies in man showing whether paracetamol causes less damage to the gastric mucosal structure than aspirin. The effects of aspirin on the gastric mucosa are well documented. We have shown that instillation of two aspirin tablets (about $600 \mathrm{mg}$ ) damages $20-25 \%$ of the surface cells within 10 minutes. ${ }^{7}$ Changes in surface cells range from focal cell disruption to microscopic erosions, the erosions being present in over $60 \%$ of biopsy specimens taken at 10 minutes. $^{7}{ }^{910}$ Scanning electron microscopy showed severe honeycombing of the gastric surface secondary to loss of normal cell apices and gastric erosions. ${ }^{7}{ }^{10} \mathrm{In}$ contrast, a much larger dose of paracetamol (1950 mg, or six tablets) damaged only $3.5 \%$ of the surface cells $(\mathrm{P}<0.01)$. Furthermore, paracetamol produced no microscopic erosions of the type produced by aspirin. Aspirin-induced damage to the gastric mucosa may be correlated with changes in the gastric mucosal barrier due to hydrogen ion movement or potential difference. ${ }^{7}$ Conversely, paracetamol in large analgesic doses (six tablets) does not damage the gastric mucosal barrier. $^{6}$
The present study indicates that large doses of paracetamol may cause some ultrastructural changes in the gastric mucosa. Infiltration of red blood cells occurred after both paracetamol and aspirin instillation and was not present in the control biopsy specimens. Nevertheless, aspirin clearly causes a much greater incidence of red blood cell infiltration. ${ }^{7} 910$

Although the effects of paracetamol differ appreciably from $c$ those of aspirin given alone, a comparison may be made between the ultrastructural changes caused by paracetamol and those caused by the instillation of $600 \mathrm{mg}$ of aspirin in a suspension of sodium bicarbonate. We have shown that $600 \mathrm{mg}$ of aspirin in $100 \mathrm{ml}$ of isotonic bicarbonate caused damage to only $3.4 \%$ of the surface cells and no gastric erosions. ${ }^{9}$ These findings are comparable to paracetamol-induced changes.

Although massive hepatic necrosis may occur when para- $\vec{\circ}$ cetamol is taken in excessive amounts, chronic hepatotoxicity is rarely reported with the routinely recommended dosage. ${ }^{12}$ Our $\vec{\omega}$ study, which shows minimal gastric mucosal damage with doses more than three times the recommended dose, justifies the continued preference for paracetamol rather than unbuffered aspirin when there is a possibility of gastric mucosal injury.

This work was supported in part by the Medical Research Service $\vec{F}$ of the Veterans Administration. We gratefully acknowledge the help $\infty$ and patient care facilities of the University of Missouri Clinical Research Centre.

Requests for reprints should be addressed to: Dr K J Ivey, $\vec{V}$ University of Missouri, Department of Medicine, Division of Gastroenterology, Columbia, Missouri 65201.

\section{References}

${ }^{1}$ Langman, M J S, Australian and New Zealand fournal of Medicine, 1976, 6, 22.

Beaver, W T, American fournal of the Medical Sciences, 1966, 251, 576

${ }^{3}$ Monograph for OTC Internal Analgesic, Antipyrectic, and Antirheumatic Products, Federal Register, vol 42 (No 131), book 2, p 35345. Washington, HEW and FDA, 1900.

${ }^{4}$ Goulston, K, and Skyring, A, Gut, 1964, 5, 463.

5 Vickers, F N, Gastrointestinal Endoscopy, 1967, 14, 94.

${ }^{6}$ Ivey, K J, and Settree, P, Gut, 1976, 17, 916.

${ }^{7}$ Baskin, W, et al, Annals of Internal Medicine, 1976, 85, 299.

${ }^{8}$ Smith, B M, et al, New England fournal of Medicine, 1971, 285, 716.

${ }^{9}$ Bowen, B K, Krause, W J, and Ivey, K J, British Medical fournal, 1977, 2, 1052

${ }^{10}$ MacKercher, P A, et al, Annals of Internal Medicine, 1977, 87, 676.

${ }_{11}$ Croft, D N, American fournal of Digestive Diseases, 1977, 22, 383.

12 Johnson, G K, and Tolman, K G, Annals of Internal Medicine, 1977, 87, 302 .

\title{
Stilboestrol and vaginal clear-cell adenocarcinoma syndrome
}

\author{
JOHN M MONAGHAN, L A W SIRISENA
}

British Medical fournal, 1978, 1, 1588-1590

\section{Summary and conclusions}

A vaginal clear-cell adenocarcinoma developed in a young woman who had been exposed in utero to maternal stilboestrol treatment. During 1940-71 in the UK some 7500 women were given stilboestrol during pregnancy. Thus more cases are likely to appear and clinicians caring for young women should be alert to this possibility.

\section{Introduction}

Stilboestrol has long been incriminated as a transplacental carcinogen. The pathogenesis of these processes is unknown. Ingestion of oestrogen in the first 18 weeks of pregnancy is thought to prevent squamous metaplasia of glandular epithelium in the upper fetal vagina, so that at puberty the ovarian hormones stimulate the persisting glandular epithelium, causing abnormal proliferation. During the 1940 s-60s stilboestrol was used in some British centres to support high-risk pregnancies. All girls resulting from these pregnancies were at risk of developing 
epithelial abnormalities in the vagina or cervix or both in adolescence, but such lesions only rarely become adenocarcinomatous. Since every young woman at risk has a positive prenatal history an efficient screening method should detect them in the presymptomatic stage.

\section{Case report}

A 25-year-old Caucasian woman was referred to us after three successive cervical smears over the past year had been reported as "suspicious, grade II-III." She had had postcoital bleeding for the past three months. Her menarche was induced at 17 years by treatment with the combined pill, which was prescribed after examination under anaesthesia and laparoscopy. Her periods were subsequently regular. She married at the age of 20 and had two uncomplicated pregnancies. Her two sons, aged $3 \frac{1}{2}$ years and 8 months, were well. She had taken the combined contraceptive pill for one year between pregnancies and again from six weeks after her second delivery until treatment was begun for the present illness. She had suffered from infantile eczema from the age of 3 months, and from allergic asthma from the age of 14 years.

Colposcopy showed an area of columnar epithelium extending to the posterior cervical lip and a hood-like area in the left posterolateral vaginal fornix. There were also areas of punctation and mosaicism on the right side of the anterior cervical lip, which biopsy showed to be moderate to severe dysplasia. The cervical smear was again "suspicious, grade II-III." Three months later a friable polypoid growth $(1 \times 1.5 \mathrm{~cm})$ was seen, arising from the left posterolateral aspect of the vagina at about the junction of the upper and middle thirds. Examination under anaesthesia a week later disclosed a thickened transverse ridge on the posterior vaginal wall, extending from the base of the growth. The growth appeared to be superficial, and histological examination of an excision biopsy specimen showed a well-differentiated, clear-cell adenocarcinoma (see figure). Cystoscopy and dilatation and curettage did not show any further abnormality.

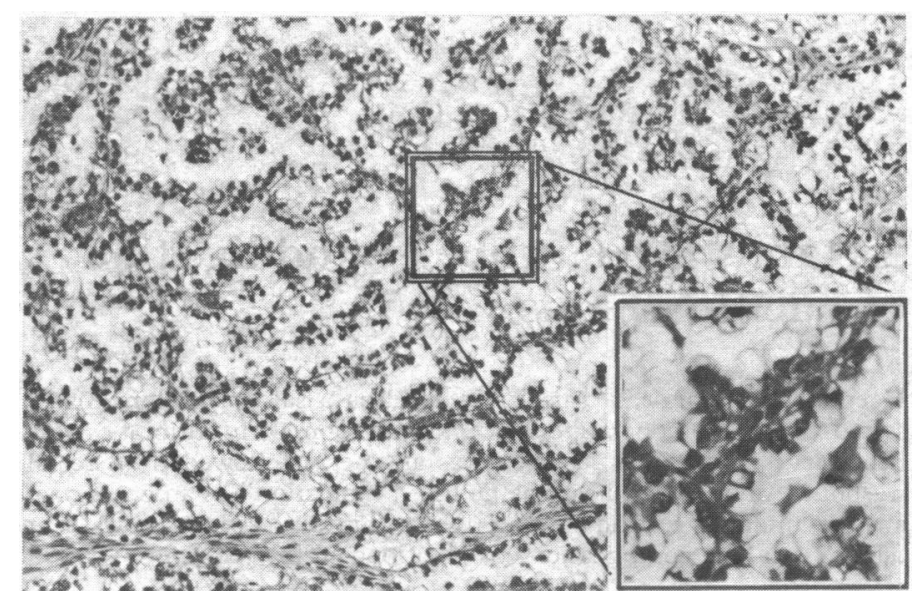

Excision biopsy specimen of vaginal clear-cell adenocarcinoma. ( $\times 8$ (inset $\times 34)$.)

An intravenous pyelogram was normal. Urinary examination showed no red cells or malignant cells. A chest $x$-ray film was normal.

Treatment consisted of radical hysterectomy and total vaginectomy, combined with pelvic node dissection. The normal-looking ovaries were hitched up in the iliac fossae above the pelvis and marked with clips to aid identification in case radiotherapy was needed later. Recovery was uneventful, and the patient was discharged home on the seventh postoperative day. Histological examination showed clear-cell carcinoma together with extensive adenosis in the middle third of the

\footnotetext{
Department of Gynaecological Oncology, Queen Elizabeth Hospital, Gateshead, Tyne and Wear NE9 6SX

JOHN M MONAGHAN, FRCSED, MRCOG, consultant surgeon

L A W SIRISENA, MS, MRCOG, registrar
}

vagina. Detailed inquiry was made into her prenatal history. Her mother had had two pregnancies. The first, six years after marriage, ended in a spontaneous abortion at 13 weeks. After two years tubal insufflation and endometrial biopsy were performed, and four years later she conceived. She was treated with stilboestrol from the fifth to 14 th weeks "to prevent a recurrent miscarriage." The pregnancy had progressed uneventfully and resulted in a normal delivery at term.

\section{Discussion}

The association between maternal ingestion of stilboestrol, which acts as a transplacental carcinogen, and the development of adenocarcinoma of the vagina in young women is well documented. Since the first case was diagnosed in 1966 over 250 cases have been recorded. ' In every case for which a detailed prenatal history was available stilboestrol had been administered before the 18th week of gestation. Data available also indicate that neither dosage nor duration of exposure is a vital factor in the development of adenocarcinoma. ${ }^{2}$ The patients' ages ranged from 7 to 29 years, with a peak incidence around 18 years. Other changes described in young women exposed to stilboestrol in utero are vaginal adenosis, extensive cervical erosion, cervical hooding, and transverse fibrous ridges of vagina and cervix, as seen in our case. It has not been established that these are premalignant lesions. Almost all the women at risk have such benign lesions, although only about $0 \cdot 1^{\circ}{ }^{\circ}$ develop adenocarcinoma. The ratio of vaginal to cervical adenocarcinoma in these women is 10:7.

Confirmed cases of vaginal adenocarcinoma associated with maternal ingestion of stilboestrol have previously been reported only from the USA, Canada, Australia, Mexico, Belgium, and France. In Britain it has been estimated that about 7500 pregnant women were treated with stilboestrol between 1940 and 1971 and a further 4500 received some other or unspecified oestrogen. Surveys have failed to yield a single case of adenocarcinoma of the vagina or cervix in women at risk. ${ }^{3}$ With reference to these figures and the American Registry reports, it has been suggested that there may be at least 10 latent cases in Britain.

Analysis of 170 cases reported by the American Tumor Registry shows that abnormal bleeding or bloodstained intermenstrual discharge was the main presenting symptom. Twentyeight patients were asymptomatic, and of these, five were detected because of abnormal smears, as in our case. The series also had a false-negative smear rate of $24^{\circ}{ }_{0}$. As the lesions are more common in the vagina than the cervix it is not surprising that a high rate of false-negative results was obtained with the usual cervical scrape. We believe that vaginal aspiration and cervical scrape in combination would increase the accuracy of smears.

The vaginal and cervical changes induced by stilboestrol are multifocal, and because the epithelia are abnormal they are not stained by iodine. This test therefore permits the selection of biopsy sites for diagnosis. Colposcopy, however, remains the most useful method for detecting the abnormal areas. The cervical epithelial dysplasia found in our patient by biopsy carried out under colposcopic control emphasises the risk of dysplasia after squamous metaplasia in areas of adenosis.

Treatment of vaginal adenocarcinoma is by surgery or radiotherapy or both, but the results are not encouraging. The youth of the patients has to ve considered in deciding the mode of treatment. At present surgery is preferred, owing to its potential for resecting the entire tumour bed and tissue at risk, including pelvic lymph nodes, while sparing the ovaries. Suitable vaginoplasty may be considered subsequently.

\section{Conclusion}

This case of vaginal clear-cell adenocarcinoma associated with maternal ingestion of stilboestrol is the first to be reported in the $\mathrm{UK}$, and we strongly suspect that there are more latent cases 
needing early diagnosis. Since all women at risk may be identified by their prenatal history screening for presymptomatic carcinoma is possible. We suggest that the best methods are visualising the vagina and cervix, cytology of both vaginal aspirate and cervical scrape, iodine staining, and colposcopy with biopsy of suspicious areas. It is imperative that all physicians treating young women should be aware of these disease processes if the maximum therapeutic benefit is to be achieved. for the histological sections; also Miss Margaret Taylor for typing the script.

\section{References}

1 Ulfelder, H, Cancer, 1976, 38, 426.

2 Poskanzer, D C, and Herbst, A L, Cancer, 1977, 39, 1892.

3 Tindall, V R, Clinics in Obstetrics and Gynaecology, 1976, 3, 246.

(Accepted 17 April 1978)

\section{SHORT REPORTS}

\section{Poncet's disease: para-infective tuberculous polyarthropathy}

In 1897 Poncet $^{1}$ introduced the term tuberculous rheumatism, meaning joint disease in patients with tuberculosis not due to tuberculous invasion of the joints-a para-infective arthropathy. The condition has rarely been referred to in British reports ${ }^{2-4}$ and is not mentioned in most current textbooks of medicine. We therefore report a child whom we believe suffered from this disease.

\section{Case report}

A 5-year-old boy, who had been born in this hospital of Pakistani parents presented with a three-week history of swelling of both knees, which had begun to ache on the day before his hospital admission. No other symptoms were complained of or admitted to on direct questioning. He had returned from Pakistan with his family four weeks previously after a six-month stay, during which he had been generally unwell with some vomiting, but the cause was unknown. He had no other medical history. He had been vaccinated with BCG in 1976, when his mother had been treated for tuberculosis. His father had died from a myocardial infarction in the same year. He had one brother aged 12 years, who was well.

On admission he was afebrile. Findings were as follows: scattered papules and pustules over the anterior surfaces of the thighs, and submandibular lymph node enlargement on the right; effusion into both knee joints, which were slightly warm and tender; and pain on movement of the left elbow, and swollen and slightly painful ankles. There was no other abnormality apart from a convergent squint of long standing. The results of investigations were as follows: $\mathrm{Hb} 9.0 \mathrm{~g} / \mathrm{dl}$; WBC $14.8 \times 10^{9} / 1$; ESR $56 \mathrm{~mm}$ in first hour blood urea and electrolyte concentrations normal; throat swab culture sterile; no pyuria in three early morning specimens; tests for serum rheumatoid factor, antinuclear factor, and Widal titres were all negative, and the ASO titre was $100 \mathrm{IU} / \mathrm{ml}$; routine viral antibody tests no significant titres. In three gastric washings Mycobacterium tuberculosis was not identified by microscopy or culture; blood culture was sterile; a chest $x$-ray film showed right hilar enlargement, with streaky shadowing of the right upper lobe; $x$-ray films of knees were normal; and a Mantoux test 1 in 1000 was strongly positive with $15-\mathrm{mm}$ induration.

Primary pulmonary tuberculosis was diagnosed and treatment was initiated with rifampicin, $450 \mathrm{mg}$ daily; isoniazid, $125 \mathrm{mg}$ daily; ethambutol, $400 \mathrm{mg}$ daily; and pyridoxine, $10 \mathrm{mg}$ daily. He improved generally and the rash on his thighs resolved, but the arthritis remained static after two weeks. A course of prednisolone, $60 \mathrm{mg} / \mathrm{day}$, was then begun and the dosage gradually reduced as the joint symptoms subsided over the next four weeks. Two months after starting antituberculous treatment he had only slight residual soft tissue swelling at the knees and his other joints were normal. The knees too had returned to normal after three months. The changes on the chest $x$-ray film resolved slowly on treatment.

\section{Discussion}

This child had a polyarthropathy associated with convincing evidence of primary pulmonary tuberculosis. The simultaneous swelling of five joints coincident with the primary complex virtually excludes direct tuberculous infection of the joints. Seronegative rheumatoid arthritis cannot be totally excluded but we believe that it is more likely that the joint features were a manifestation of tuberculous allergy. The rash on the thighs appeared typical of papulonecrotic tuberculid ${ }^{5}$ and resolved with antituberculous chemotherapy, giving further evidence of tuberculous allergy. The possibility of tuberculosis should be considered whenever a patient has a polyarthropathy of obscure cause.

We thank Dr B Taylor for introducing us to the earlier reports on Poncet's disease.

1 Poncet, A, Congrès Français de Chirurgie, 1897, p 732.

2 Sheldon, W, Lancet, 1946, 1, 119.

${ }^{3}$ Wilkinson, M C, Tubercle, 1967, 48, 297.

4 Isaacs, A J, and Sturrock, R D, Tubercle, 1974, 55, 135.
${ }^{5}$ Rook, A, Wilkinson, D S, and Ebling, F J G, Textbook of Dermatology, vol 1, p 625. London, Blackwell, 1975.

(Accepted 15 February 1978)

Department of Paediatrics, Dudley Road Hospital, Birmingham B18 7QH

C A BLOXHAM, MB, MRCP, senior house officer

D P ADDY, MRCP, DCH, consultant paediatrician

\section{Tetanus after rubber-band ligation of haemorrhoids}

Haemorrhoidectomy is usually regarded as a safe operation. Slack ${ }^{1}$ stated that no preoperative bowel sterilisation with antibiotics was necessary; all that was required was an enema followed by a rectal $N$ washout. Among complications he listed "infection" as an occasional abscess under a redundant skin fold. This case report shows that tetanus can be a complication of operations on the rectum.

\section{Case report}

A 33-year-old housewife was admitted to hospital because of a two-day 0 history of difficulty in opening her mouth and in swallowing, neck pain, neck and abdominal muscle stiffness, and excessive sweating. Rubber-band $\mathscr{D}$ ligation of internal haemorrhoids had been performed nine days previously (seven days before symptoms began). She had had no other injury, and had $\bar{D}$ not been immunised against tetanus. On admission she had clinical tetanus. $\vec{\Phi}$ She had a particularly severe spasm of the jaw on trying to remove her $\Omega$ dentures. She was treated with penicillin, tetanus immunoglobulin, and $\mathbb{D}$ originally with intravenous diazepam. The symptoms were not controlled, so endotracheal intubation was performed followed by paralysis, intermittent positive-pressure respiration, and tracheostomy. Progress was complicated $ᄋ$ by an unstable blood pressure and a lower-lobe pneumonia, but the relaxants could be discontinued after 25 days and progress thereafter was uneventful.

\section{Comment}

The source of clinical tetanus may be difficult to determine. In our experience $10 \%$ of patients have no detectable wound. Spores of 